\title{
Leitura crítica de texto multimodal em língua inglesa: uma proposta didática
}

\author{
Critical reading of multimodal text in English: a didactic \\ proposal
}

\author{
Paula Kracker Francescon ${ }^{1}$ \\ Déborah Caroline Cardoso Pereira Rorato ${ }^{2}$
}

\begin{abstract}
RESUMO: Inserido na área da Linguística Aplicada, no campo de ensino e aprendizagem de língua estrangeira, com foco em multiletramentos, este trabalho tem como objetivo principal apresentar uma proposta didática de leitura em língua inglesa a partir de conceitos de multimodalidade e letramento crítico. Essa proposta parte de uma cena de filme, considerado como texto multimodal, para desenvolver trabalho que proporcione reflexão sobre questões de preconceito, retratado em sociedade diferente da dos alunos. Com isso, buscamos propor uma atividade de ensino de língua inglesa que contemple as linguagens utilizadas em textos multimodais, assim como reflexão crítica sobre um tema que entendemos necessário de ser debatido em sala de aula.
\end{abstract}

PALAVRAS-CHAVE: Letramento Crítico. Multiletramentos. Proposta Didática.

ABSTRACT: Set in the area of Applied Linguistics, in the field of foreign language teaching and learning, with focus on multiliteracies, this paper's objective is to present a didactic proposal of reading in foreign language based on concepts of multiliteracies and critical literacy. The proposal presented uses a film scene, considered as multimodal text, to develop activities that enable reflection about issues of prejudice, pictured in a society different from the one the students live in. With this didactic proposal, we aim at developing an English teaching activity which comprehends languages used in multimodal texts, as critical reflection about a theme that must be discussed in class.

KEYWORDS: Critical Literacy. Multiliteracies. Didactic proposal.

\section{Introdução}

As novas tecnologias têm influenciado $o$ processo de ensino e aprendizagem de línguas, como já foi consolidado por meio de pesquisas desenvolvidas na área (NASCIMENTO; BEZERRA; HEBERLE, 2011; OLIVEIRA,

1 Doutoranda em Estudos da Linguagem na Universidade Estadual de Londrina (UEL). Contato: francescon.paula@gmail.com

2 Doutoranda em Estudos da Linguagem na Universidade Estadual de Londrina (UEL). Contato: deborahccp@hotmail.com 
2013; LOPES, 2014), disciplinas presentes nas grades curriculares e pela inserção (natural ou artificial) do mundo digital no mundo escolar. Diversas são as razões para este fenômeno: orientações governamentais acerca do ensino por meio de textos multimodais (OLIVEIRA, 2013); a crescente substituição dos textos impressos para os digitais; o aumento no número de computadores e acesso à internet nas escolas (LOPES, 2014), bem como a valorização do aspecto visual e de diferentes práticas textuais, como vídeos, blogs, etc. (NASCIMENTO; BEZERRA; HEBERLE, 2011).

Vale mencionar, no entanto, que mesmo diante desses fatores, estamos conscientes de que as tecnologias não atingem a população como um todo, culminando ainda em uma nova face da exclusão social. Da mesma forma, sabemos que a língua inglesa, assim como o domínio digital e tecnológico, é fator que pode gerar exclusão, uma vez que o acesso a esses recursos na sociedade contemporânea é considerado essencial, mas nem sempre abrange toda a população.

Ribeiro (2009) explica que, com a advento do computador, nós passamos a ter mais possibilidades de texto no sistema de mídia, ou seja, antigamente as opções se limitavam ao texto impresso e oral, atualmente temos outras mídias como a televisão, a internet, o rádio. Essas novas possibilidades de texto podem contribuir para o processo de ensinoaprendizagem. No entanto, como professores, em sua maioria imigrantes digitais, estamos lidando com estudantes nativos digitais, o que gera uma incompreensão, como defende Prensky (2001). Este pesquisador explica que as perspectivas em relação a aprendizagem, trabalhos, raciocínio, atividades se diferem entre professores e alunos, imigrantes e nativos digitais.

Além desta diferença entre as habilidades tecnológicas docente e discente, pensamos que a tecnologia pode incluir ou excluir cidadãos das atuais práticas sociais, e o mesmo ocorre em relação ao conhecimento da língua inglesa. Portanto, compartilhamos com El Kadri (2011) o entendimento de que tecnologia e inglês são aspectos inter-relacionados capazes de gerar (des)igualdades. Por essas e por outras razões já mencionadas, pensamos que 
cabe a escola e ao professor inserirem diferentes mídias no processo de ensino aprendizagem, visando a inserção e a capacitação de estudantes em relação aos diferentes gêneros de texto e do conhecimento da língua inglesa.

A partir do exposto, os objetivos deste trabalho são proporcionar atividades de leituras críticas de texto multimodal em língua inglesa; possibilitar aos alunos reflexões sobre o tema preconceito; desenvolver com os alunos habilidades de leitura multimodal, pela junção de linguagem verbal e visual proporcionada pela cena do filme. Para isso, o texto está organizado em três partes, além desta seção introdutória. Primeiramente, discutiremos no referencial teórico questões acerca dos Multiletramentos, da Multimodalidade e do Letramento Crítico. Em seguida, apresentaremos a proposta didática com seus objetivos e justificativa. Ao final, esboçaremos uma reflexão acerca da produção deste estudo. Com esse trabalho, esperamos oferecer um exemplo de atividade que pode ser facilmente desenvolvida com alunos do ensino médio, visando proporcionar reflexões sobre as atividades de leitura em língua inglesa que objetivem possibilitar aos alunos leituras críticas de multimodais.

\section{Referencial teórico}

O referencial teórico deste trabalho se centra em questões de multiletramentos, englobando aspectos de multimodalidade, uma vez que a atividade de leitura proposta se baseia em um texto multimodal, visando a proporcionar leituras de variadas formas de linguagens. Também apresentamos reflexões sobre letramento crítico, pois a proposta de leitura objetiva proporcionar possibilidades de leituras em variados níveis de compreensão, inclusive o crítico.

\section{Multimodalidade e multiletramentos no contexto escolar}

Pensar em multimodalidade e multiletramentos no processo de ensinoaprendizagem é mais do que uma ação ou um anseio isolado, é uma orientação 
curricular do próprio Estado. Segundo Oliveira (2013), os Parâmetros Curriculares Nacionais e as Orientações Curriculares para o Ensino Médio, documentos que orientam o ensino, centralizam a área de Linguagens (códigos e suas tecnologias) na abordagem de gêneros, com foco nos letramentos múltiplos. El Kadri (2011), por sua vez, afirma que os documentos oficias enfatizam a necessidade de práticas de multiletramentos para o ensino de língua inglesa. Em outras palavras, o ensino deve ser realizado por meio da exploração de modalidades verbais e não-verbais da linguagem.

A presença cada mais vez mais significativa dessas modalidades em suportes e gêneros digitais nos levam a enxergar a partir da ótica da inclusão digital e dos letramentos que vão além da escrita e da leitura. Além disso, ao pensarmos na língua inglesa como um caminho para cidadania $\mathrm{e}$ emponderamento, assim como o domínio tecnológico, entendemos, como El Kadri (2011), a tecnologia e a língua inglesa como aspectos inter-relacionados que podem provocar (des)igualdades.

Kress e van Leeuwen (2006) investigaram diferentes modos de comunicação, superando a habilidade verbal, e desenvolveram a teoria da multimodalidade (KRESS; VAN LEEUWEN, 2006; KRESS, 2010). Para eles, multimodalidade é a inter-relação entre diferentes modos semióticos (OLIVEIRA, 2013), ou seja, um texto que integra recursos semióticos, como a escrita, o visual, a oralidade, o som, o gesto. Por isso, a complexidade de interpretação e consumo dos textos multimodais, uma vez que estes exigirão do leitor domínio de diferentes habilidades e capacidades para fazer significar esses modos de significação (ROJO, 2012).

Tais textos multimodais, de acordo com Oliveira (2013), não são devidamente explorados no contexto escolar, mesmo estando nitidamente presentes na vida social. Por isso, a pesquisadora conclui que a escola deve proporcionar uma prática didático-pedagógica para incentivar a produção e interpretação desses textos. Da mesma forma, Nascimento, Bezerra e Heberle (2011) enfatizam que a interpretação das informações não-verbais não é 
implícita, e que cabe a escola contribuir para esse conhecimento que desenvolverá a representação do mundo social dos alunos.

A respeito dos multiletramentos, na década de 90 , este conceito foi desenvolvido como uma pedagogia por um grupo de estudiosos chamado Grupo Nova Londres (CAZDEN et al., 1996). O termo multiletramentos é encarado por esses estudiosos não somente como uma multiplicidade de canais e mídias de comunicação, mas também como a diversidade cultural e linguística. Assim, a pedagogia de multiletramentos vai muito além da língua, ela é adaptada de acordo com o contexto, a cultura, a cognição, o social. Isto ocorre porque as informações como o texto, a imagem, o som são vistos por eles como a maneira pela qual a criação de sentidos ocorre e reformula a nossa forma de usar a língua.

Seguindo o estudo de Cazden et al. (1996), Rojo (2012, p. 3) compartilha o sentido de multiletramentos pautado em dois pólos: a multiplicidade cultural e a multiplicidade semiótica ou de linguagens. A multiplicidade de culturas diz respeito a mistura e ao hibridismo de raças e culturas dentro da sala de aula, já observada há bastante tempo, mas "totalmente despercebida ou propositalmente ignorada". Enquanto a multiplicidade de linguagens se refere à multimodalidade, "ou seja, textos compostos de muitas linguagens (ou modos, ou semioses) e que exigem capacidade e práticas de compreensão e produção de cada uma delas (multiletramentos) para fazer significar" (ROJO, 2012, p. 5).

Seguindo esta linha de raciocínio, Dionísio (2011) relaciona o termo multiletramentos a habilidade de construir sentidos a textos multimodais. Para ela, mais do que os textos, as ações sociais e, consequentemente, os gêneros textuais são multimodais. Ou seja, como nossas relações sociais integram mais de uma representação, e os gêneros textuais são oriundos de tais relações, ambos são multimodais. Assim, ser ou tornar-se multiletrado é saber agir e criar sentidos diante de textos e (rel)ações sociais multimodais.

Cazden et al. (1996) acreditam ainda que a multiplicidade linguística e cultural é essencial para o desenvolvimento crítico da língua e buscam 
relacionar multiletramentos às mudanças sociais por meio da superação das abordagens de ensino tradicionais. Para estes estudiosos, estamos vivendo uma nova natureza de vida e de trabalho, oriunda das novas tecnologias e das novas relações sociais, que implicam em novas formas de usar as linguagens. Para nós, professores, cabe, então, não somente oportunizar aos estudantes acesso a essas novas linguagens, mas também conduzi-los a negociação, ao engajamento crítico.

Ao pensarmos no papel e na formação docente, Dionísio (2011) defende que para trabalhar com multiletramentos e multimodalidade é necessário que os professores tenham conhecimento e consciência de como usá-los. Fazer uso de tecnologias, por exemplo, exigirá dos estudantes diferentes letramentos, integrando textos verbais, orais, escritos, visuais. Ou seja, como afirma Rojo (2012), os letramentos passam a ser multiletramentos. Por isso, além de propor novas ferramentas (áudio, vídeo, imagem, etc.), não devemos apenas unir textos multimodais, mas observar os "princípios de organização" (DINONÍsIO, 2011, p. 150) desses textos e desenvolver novas práticas de produção e análise crítica (ROJO, 2012).

\section{Letramento crítico, multimodalidade e multiletramentos}

Rojo (2012) problematiza o uso da pedagogia dos multiletramentos em sala de aula, uma vez que os alunos já estão inseridos no mundo digital, tecnológico. Para ela, ao invés de proibir o uso, nós, professores, devemos investigar maneiras de usar efetivamente a internet e/ou o celular para o ensino, e, a fim de atingir tal objetivo, é necessário o letramento crítico para que os alunos se tornem analistas críticos.

Por isso, acreditamos que objetivar uma educação multimodal e multiletrada é pensar em uma educação crítica. Primeiramente, porque os jovens, nativos digitais, já estão naturalmente imersos às ferramentas digitais e tecnológicas (ROJO, 2012) e também por terem, de maneira geral, capacidade de aprender quaisquer habilidades e conhecimentos que thes interessem 
(PRENSKY, 2010), portanto, contato e habilidade com o digital e o tecnológico eles já possuem, cabe a nós, professores, otimizar a qualidade do que é produzido, compartilhado e aprendido neste contexto.

Em nossa concepção, possibilitar práticas de leitura crítica aos alunos faz parte de agenda mais abrangente do letramento crítico. Para Giroux (1993, p. 367) o "letramento se torna crítico no nível em que torna problemática toda estrutura e prática de representação", ou seja, quando não considera toda e qualquer representação e significação de mundo como garantidas e inquestionáveis (REIS, 2010). Para Gee (1993), nossas construções de significados são baseadas em fatores históricos e sociais, e os valores e crenças que temos são fruto de práticas sociais conduzidas historicamente por grupos de pessoas que visavam privilégios e autoridade sobre outros grupos e suas práticas. Assim, recebemos essa "herança" e a aplicamos em nosso cotidiano, sem refletir sobre suas origens, efeitos e significados. Nesse sentido, letramento crítico se caracteriza pelo constante questionamento, análise e reflexão de informações, eventos e ações sociais com os quais entramos em contato.

De acordo com a teoria pedagógica freireana (FREIRE, 1967, 1987; FREIRE; MACEDO, 1990), esse questionamento contribui para conscientização e resistência em relação a pressupostos construídos historicamente. A partir disso, o indivíduo pode rumar em direção à emancipação, transformação e acesso, já que ele começa a construir conhecimento e adquirir habilidades que contribuem com seu autoempoderamento (GIROUX, 1993).

Assim, com base nessas características relacionadas ao letramento crítico, avaliamos a importância de trabalho docente que possibilite aos alunos práticas de leitura crítica, que questione os pressupostos sociais que já estão enraizados no saber comum de uma sociedade e que, normalmente, carregam interesses próprios de alguns grupos específicos dessa comunidade. Portanto, entendemos que esse saber comum não precisa, necessariamente, ser perpetuado, e o ensino deve oferecer meios para que os alunos-cidadãos possam se tornar ativos e críticos. 
Wallace (1992) e Figueiredo (2000) apontam as aulas de línguas estrangeiras podem ser lugar privilegiado para o desenvolvimento de letramentos críticos, já que os alunos tem a oportunidade de entrar em contato com textos representativos de outras culturas, outras formas de representar 0 mundo, contribuindo, assim, para sua formação crítica. Dessa forma, o trabalho com leitura em língua estrangeira pode

\begin{abstract}
ajudar os leitores em inglês como língua estrangeira a se sentirem mais confiantes em tomar posições mais assertivas contra o texto, encorajá-los a sentirem que eles têm opções na maneira em que eles escolhem ler os textos, e ajudá-los a se sentirem em uma relação mais igual com o escritor (WALLACE, 1992, p. 80).
\end{abstract}

Pennycook (2001, p. 5), ao listar os desafios da Linguística Aplicada Crítica, aponta como um deles encontrar "formas de entender a relação entre conceitos de sociedade, ideologia, capitalismo global, colonialismo, educação, gêneros, racismo, sexualidade, classes, e expressões na sala de aula, traduções, conversas, gêneros, ensino e aprendizagem de segunda língua, textos midiáticos". Assim, podemos considerar a lista do autor como temáticas a serem problematizadas em sala de aula, buscando refletir sobre as significações atribuídas histórica e socialmente a esses temas.

\title{
Proposta de atividade de leitura de texto multimodal
}

Neste tópico, apresentaremos a atividade de leitura de texto multimodal em língua inglesa, assim como a contextualização de sua produção e comentários sobre as questões elaboradas, a fim de proporcionar uma visão ampla da proposta.

A seleção do texto multimodal/cena de filme que embasa as atividades de leitura foi realizada por retratar preconceito, um tema que a literatura sobre letramento crítico aconselha ser discutido em sala de aula. A decisão por um texto multimodal se deve ao fato desse tipo de texto estar cada vez mais presente na vida diária dos alunos. O texto multimodal, composto por mais de 
um modo de significação (no caso da cena de filme, composto por linguagem verbal e visual), proporciona multiplicidade de leituras, possibilitando aos alunos refletir sobre as significações que podem ser construídas pela utilização simultânea de mais de uma modalidade de linguagem.

As atividades foram elaboradas com base na teoria do contexto da situação (context of situation, HALLIDAY, 1989) que, a partir de concepção sociossemiótica de linguagem, preconiza refletir sobre três instâncias relacionadas ao texto: o campo, que se refere ao que está acontecendo, à natureza da ação social que está ocorrendo; os participantes, que se relaciona a quem está tomando parte da ação, a natureza dos participantes, seus status e papéis: qual a relação entre os participantes, o tipo de discurso que eles estão tomando e o grupo de relações sociais em que eles estão envolvidos; e o modo, que se refere ao papel da língua, o que os participantes esperam que a língua faça por eles naquela situação.

A seguir, apresentamos a atividade e comentamos cada questão, para uma completa compreensão dos objetivos de cada uma. Nas proposições de alternativas, os alunos podem escolher quantas opções acharem pertinentes para responder à questão e, ainda, oferecer explicação para suas respostas.

\section{Atividade: Cena do filme Crash (2004)}

1) Watch a scene of the film Crash and discuss the following questions:

How can you describe the scene? Is it a scene of humor, drama, suspence, etc.? Is the situation funny, calm, tense, nervous, etc.

Who are the people involved in the scene (mention their relations, jobs, social positions, etc.)?

2) Watch the scene and fill the gaps 3 :

A socialite (Sandra Bullock) and a District Attorney (Brandon Fraser) are carjacked at gunpoint by two black teenagers. Jean (Sandra) takes out her anger on a Mexican locksmith who is changing the door locks at their house.

3 Para este trabalho, deixamos as palavras/expressões a ser completadas em negrito. 
Jean: I want the locks changed again in the morning.

Rick: You what? Look, why don't you just go lie down, huh? Have you checked on James?

Jean: Well of course I've checked on James. I've checked on him every five minutes since we've been home. Do not patronize me. I want the locks changed again in the morning.

Rick: Shhh. It's ok. Just go to bed, all right?

Jean: You know what, didn't I just tell you not to treat me like a child?

Maria: I'm sorry Mrs. Jean. It's okay I go home now?

Rick: It's fine. Thank you very much for staying Maria.

Maria: You're welcome. No problem. Goodnight Mrs. Jean.

Jean: Goodnight.

Rick: [to Maria] We'll see you tomorrow.

Jean: I would like the locks changed again in the morning. And you know what, you might mention that we'd appreciate it if next time they didn't send a gang member...

\section{Rick: A gang member?}

Jean: Yes, yes.

Rick: What do you mean? That kid in there?

Jean: Yes. The guy in there with the shaved head, the pants around his ass, the prison tattoos.

Rick: Those are not prison tattoos.

Jean: Oh really? And he's not gonna go sell our key to one of his gang banger friends the moment he is out our door?

Rick: You've had a really tough night. I think it would be best if you just went upstairs right now and...

Jean: And what? Wait for them to break in? I just had a gun pointed in my face!

Rick: You lower you voice!

Jean: ... and it was my fault because I knew it was gonna happen. But if a white person sees two black men walking towards her and she turns and walks in the other direction, she's a racist, right? I got scared and I didn't say anything and ten seconds later I had a gun in my face. Now I am telling you, your amigo in there is gonna sell our key to one of his homies and this time it'd be really fucking great if you acted like you actually gave a shit!

Source: https://www.youtube.com/watch?v=N-Umf_chNHw

3) The situation pictured in the scene is:

a) a nervous moment for Jean, who is afraid of another violent action. 
b) an affective situation for Jean, because it disturbed her feelings.

b) a mix of personal and professional event for Rick, who appears to be calm and is working on the crime he suffered.

c) an ordinary situation for the locksmith, who is only doing his job.

4) About Jean's relations with the participants of the event:

a) Jean feels superior to Maria because of her social position.

b) Jean feels superior to the locksmith because of his nationality.

c) Jean feels superior to her husband's black colleagues because of their ethnicity.

5) Why does Jean consider the locksmith a gang member / a criminal?

a) because of her prejudice against Latin people in the USA.

b) because of her prejudice against people with the locksmith's appearance (shaved head, pants around his ass, tattoos), no matter if they are Latin or not.

c) because of her prejudice against the locksmith's appearance, considering that he is Latin.

6) Jean's statement "and it was my fault because I knew it was gonna happen. But if a white person sees two black men walking towards her and she turns and walks in the other direction, she's a racist, right? I got scared and I didn't say anything and ten seconds later I had a gun in my face", shows that:

a) she is against any kind of prejudice.

b) she is conscious about a racist action, but considers it is ok to act like this following an episode of violence that she had suffered.

c) she considers that black people always commit crimes.

7) In your opinion, when Jane is talking about the black people, why is the black policewoman focused on the scene?

8) When Jean uses the word amigo to talk about the locksmith, she:

a) means that the locksmith is a nice and friendly man.

b) uses it to depreciate him and Latin people in general. 
c) shows her prejudice in relation to the locksmith.

d) means that her husband has a trustworthy friend.

9) In your opinion, how does Jean feel when the locksmith leaves the door keys?
a) embarrassed
b) sorry
c) confronted
d) furious
e) glad
f) relieved
g) satisfied
h) inadequate
i) frustrated Why?

A atividade 1 objetiva uma contextualização sobre a cena do filme apresentada. Mesmo ainda sem contato com o texto verbal escrito, as imagens da cena dão pistas sobre a situação retratada e as questões propostas podem contribuir para que os alunos comecem a refletir sobre ela, discutindo sobre o tipo de cena e seus participantes. A segunda atividade é a apresentação do texto verbal das falas das personagens da cena por meio de um proposta de compreensão auditiva, meio pelo qual é possível contribuir para o desenvolvimento dessa habilidade.

A questão 3 propõe análise sobre a situação representada na cena do filme, que pode ser relacionado ao aspecto campo da teoria do contexto da situação (HALLIDAY, 1989). Esse aspecto visa a examinar a natureza da ação social, do evento que está sendo retratado. Nesse caso, focamos nas possíveis representações da situação para os principais envolvidos na cena do filme, proporcionando relacionar essa reflexão com a realizada na atividade 1 sobre a descrição da cena.

A proposição 4 pretende levar à reflexão sobre a relação entre os participantes da situação, remetendo à questão 1 , na qual se discutiu sobre as personagens da cena. $O$ foco dessa proposição é levar o leitor a problematizar questões de preconceito apresentadas pela personagem principal Jean em relação a outros participantes da situação. Em continuação a essa discussão, a questão 5 tange somente a relação da personagem Jean e do chaveiro, questionando a relação de preconceito entre eles. Problematizar a questão da nacionalidade latina do chaveiro nos Estados Unidos é importante e leva os 
alunos a refletirem sobre outra realidade, outra cultura. Assim, é possível desenvolver atividades sobre a questão da imigração nos EUA, o que os estadunidenses pensam sobre os latinos que vivem em seu país, etc.

A atividade 6 enfoca uma parte específica de uma fala da personagem Jean, na qual ela relembra o episódio de violência pelo qual passou, se referindo a um momento racista. Dessa forma, a questão pretende fazer o leitor analisar a fala de Jean e refletir sobre o que ela pensa sobre o episódio, atos de racismo e a relação entre negros e crimes. Em relação ao mesmo momento da cena, a questão 7 remete a um aspecto da multimodalidade do texto, já que durante a fala de Jean uma policial negra é focada. Por isso, a pergunta pede ao leitor para refletir sobre esse aspecto fílmico, justificando seu objetivo.

A questão 8 foca o uso que Jean faz de uma palavra em espanhol para se referir ao chaveiro. Ela o referencia com o léxico amigo, e a pergunta visa a possibilitar ao leitor notar a ironia usada pela personagem ao se referir ao chaveiro e sua raiva ao perceber que seu marido não está dando atenção para seu pedido. A última pergunta também se refere à relação entre Jean e o chaveiro. O final da cena retrata o chaveiro deixando as chaves da nova fechadura para Jean, depois de ter ouvido seu pedido de nova troca de fechadura pela falta de confiança no chaveiro. Ao deixar as chaves, as expressões faciais do chaveiro e de Jean são instigantes e possibilitam variadas interpretações. Assim, a pergunta pede que o leitor tente inferir os sentimentos de Jean naquele instante, apenas 'lendo' suas expressões faciais. Essa é uma oportunidade de possibilitar aos alunos leituras de imagens.

\section{Considerações finais}

As identidades docentes estão em constante mudança. O mesmo ocorre com as identidades discentes. Alunos já não sentam individualmente, em linhas retas e em silêncio durante as aulas, o material didático não é mais uma verdade absoluta, as informações não são transmitidas pelos professores, como na chamada educação bancária (FREIRE, 1987) ou na velha pedagogia 
(PRENSKY, 2010), pelo menos não deveriam, uma vez que com o advento das novas tecnologias, as informações estão a todo tempo em todo lugar.

Portanto, pensar no papel da escola e no do professor é pensar em formar, educar alunos para se tornarem cidadãos aptos a agir no mundo contemporâneo, ou seja, um mundo tecnológico e digital, sendo capazes de produzir e consumir textos multimodais de forma crítica. Por isso, como defendem estudiosos (ROJO; MOITA LOPES, 2004; LOPES, 2014), os letramentos tradicionais já não são mais suficientes.

A partir disso, neste trabalho, apresentamos uma proposta didática de leitura em língua inglesa que visou englobar questões de multimodalidade e, assim, multiletramentos, além de letramento crítico. Consideramos que textos multimodais devem ser explorados em sala de aula a fim de propiciar aos alunos capacidades de leituras de textos que englobem várias formas de linguagem que são correntes em nosso cotidiano. Também, pensamos ser importante proporcionar aos alunos oportunidades de desenvolvimento de leituras críticas, as quais, no caso exposto neste artigo, partem de problematização da temática racismo.

Para desenvolvermos esta educação nos moldes de uma sociedade digital e tecnológica, visando diversos níveis de (multi)letramentos, pensamos ser necessária uma formação docente voltada à nova realidade educacional, concomitantemente a um investimento financeiro e estrutural em tecnologias e suas manutenções nas escolas e universidades (visando a formação de todo o ciclo educacional: professores universitários, futuros professores, professores e alunos). Somente professores com habilidades de manuseio didáticopedagógico das tecnologias serão capazes de fazer bom uso delas em sala de aula.

Finalmente, ao refletirmos acerca das atuais relações sociais, acreditamos que tanto a habilidade de se falar inglês como de fazer uso de ferramentas tecnológicas e digitais são divisores sociais, ou seja, da mesma maneira que criam novas oportunidades, podem excluir aqueles que não as dominam. Portanto, cabe a nós, professores, contribuirmos para esta formação 
dos nossos alunos, mesmo enfrentando condições educacionais e estruturais muito precárias, como afirma Rojo (2012), conseguiremos superá-las frente à vontade e ao esforço.

\section{Referências}

CAZDEN, C. et al. A pedagogy of multiliteracies: designing social futures. Harvard Educational Review, Cambridge, v. 66, n. 1, p. 60-92, 1996.

CRASH. Direção: Paul Haggis. Produção: Paul Haggis e Don Cheadle. Lions Gate Films, 2004. $113 \mathrm{~min}$.

DIONÍSO, A. P. Gêneros textuais e multimodalidade. In: KARKOVSKI, A. M.; GAYDECZKA, B.; BRITO, K. S. (Org.). Gêneros textuais. reflexões e ensino. 4. ed. São Paulo: Parábola editorial, 2011. p. 137-152.

EL KADRI, M. S. Developing professional skills: English and technology. In: RIOS-REGISTRO, E. S. et al. (Org.). Connecting ide@s: tools for teaching English in a contemporary society. Londrina, UEL, 2011. p. 15-35.

FIGUEIREDO, D. C. Critical discourse analysis: towards a new perspective of EFL reading. Ilha do Desterro, Florianópolis, n. 38, p. 139-154, jan./jun. 2000.

FREIRE, P. Educação como prática libertadora. Rio de Janeiro: Paz e Terra, 1967.

. Pedagogia do oprimido. 17. ed. Rio de Janeiro: Paz e Terra, 1987.

FREIRE, P.; MACEDO, D. Alfabetização: leitura do mundo leitura da palavra. Trad. Lólio Lourenço de Oliveira. Rio de Janeiro: Paz e Terra, 1990.

GEE, J. P. Postmodernism and literacies. In: LANKSHEAR, C.; MCLAREN; P. L. (Eds.). Critical Literacy: politics, praxis, and the postmodern. Albany: State University of New York Press, 1993. p. 271-295.

GIROUX, $\mathrm{H}$. Literacy and the politics of difference. In: LANKSHEAR, C.; MCLAREN, P. L. (Eds.). Critical Literacy. politics, praxis, and the postmodern. Albany: State University of New York Press, 1993. p. 367-377.

HALLIDAY, M. Context of Situation. In: HALLIDAY, M.; HASSAN, R. Language, context and text: aspects of language in a social-semiotic perspective. Oxford: Oxford University Press, 1989. p. 3-14.

KRESS, G.; VAN LEEUWEN, T. Reading images: the grammar of visual design. 2. ed. London, New York: Routledge, 2006. 
KRESS, G. Multimodality: a social semiotic approach to contemporary communication. London, New York: Routledge, 2010.

LOPES, J. G. Protótipo de material didático digital interativo para ensino de língua portuguesa. EmRede, revista de educação a distância, Porto Alegre, v. 1, n. 1, p. 92-108, 2014.

NASCIMENTO, R. G.; BEZERRA, A. S; HEBERLE, V. M. Multiletramentos: iniciação à análise de imagens. Linguagem \& Ensino, Pelotas, v.14, n.2, p. 529552, jul./dez. 2011.

OLIVEIRA, D. M. Gêneros multimodais e multiletramentos: novas práticas de leitura na sala de aula. In: FÓRUM IDENTIDADES E ALTERIDADES, 6., CONGRESSO NACIONAL DE EDUCAÇÃO E DIVERSIDADE, 2., 2013. Anais ... Itabaiana/SE, 2013. p. 1-8.

PENNYCOOK, A. Critical Applied Linguistics: a critical introduction. Mahwah, New Jersey: Lawrence Erlbaum Associates, 2001.

PRENSKY, M. Nativos Digitais, Imigrantes Digitais. On the Horizon, NCB University Press, 2001. Disponível em: <http://www.colegiongeracao.com.br/ novageracao/2_intencoes/nativos.pdf>. Acesso em: 10 set. 2016.

PRENSKY, M. O papel da tecnologia no ensino e na sala de aula. Conjectura, Caxias do Sul, v. 15, n. 2, p. 201-204, maio/ago. 2010.

REIS, S. Valorização do professor? Uma leitura resistente de um texto unidirecional. Linguagem \& Ensino, Pelotas, v.13, n.2, p.495-523, jul./dez, 2010.

RIBEIRO, A. E. Letramento digital: um tema em gêneros efêmeros. Revista da ABRALIN, Brasília, v.8, n.1, p. 15-38, jan./jun, 2009.

ROJO, R. H. R. Pedagogia dos multiletramentos, diversidade cultural e de linguagens na escola. In: ROJO, R. H. R.; MOURA, E. (Org.). Multiletramentos na escola. São Paulo: Parábola Editorial, 2012. p. 11-31.

ROJO, R.H.R.; MOITA LOPES, L. P. da. Linguagens, códigos e suas tecnologias. In: BRASIL. MEC (Org.). Orientações Curriculares do Ensino Médio. Brasília, 2004. p. $14-59$.

WALLACE, C. Critical literacy awareness in the EFL classroom. In: FAIRCLOUGH, N. Critical Language Awareness. London: Longman, 1992. p. 59-92. 